\title{
Sinter-Bonding of AISI 316L and 17-4 PH Stainless Steels
}

\author{
Aneta Szewczyk-Nykiel and Rafał Bogucki
}

(Submitted February 8, 2018; in revised form May 16, 2018; published online August 28, 2018)

\begin{abstract}
The sinter-bonding method was used to produce AISI 316L/17-4 PH components by conventional powder metallurgy technology. The production process consisted of following steps: the powder layering, copressing and co-sintering processes. The co-sintering process was carried out at different sintering temperatures $\left(1200,1250\right.$ and $\left.1300{ }^{\circ} \mathrm{C}\right)$, and times $(60,90$ and $120 \mathrm{~min})$ in hydrogen atmosphere. The effect of co-pressing and co-sintering conditions on the ability to create a permanent connection between AISI 316L and 17-4 PH stainless steels was investigated. The densification, dimensional change and microstructural evolution of sintered AISI 316L/17-4 PH components were studied. The increase in co-pressing pressure as well as using of the longer time and the higher temperature of co-sintering process contributed to increase in AISI 316 L/17-4 PH component density. The dilatometric study as well as dimensional changes measurements revealed an appropriate sintering compatibility for AISI 316L and 17-4PH steels when the sintering process was carried out at the temperature of $1200{ }^{\circ} \mathrm{C}$ for time ranging from 60 to $120 \mathrm{~min}$ and at $1250{ }^{\circ} \mathrm{C}$ for shorter sintering times. The sintering at temperature of $1300{ }^{\circ} \mathrm{C}$ (regardless of other manufacturing conditions) led to a significant deviation from the cylindrical shape of samples, as a result of difference of shrinkage of AISI 316L and 17-4 PH steels. Microstructural study indicated that AISI 316L and 17-4 PH steels creates a good diffusion joint (without any cracks and warpage) during the hightemperature sintering process. Nickel diffusion takes place from the AISI 316L to 17-4 PH stainless steel, and copper and molybdenum diffuse in opposite direction of nickel diffusion. It is possible to achieve a solid connection between two materials exhibiting difference in chemical composition by using sinter-bonding and conventional powder metallurgy technology.
\end{abstract}

Keywords sinter-bonding, joining of dissimilar materials, powder metallurgy, AISI 316L, 17-4 PH, microstructure, densification

\section{Introduction}

The demands of market in an area of engineering materials are getting greater. Hence, it is important that the designed and fabricated materials could fulfill desirable requirements in specific applications. It is obvious that none of the materials fully satisfy all requirements but a combination of different properties is possible to obtain in composites. They are very attractive for lots of applications due to unique properties.

It can also be seen the rapid growth of interest in the area of joined materials (Ref 1-26). These materials are increasingly used in engineering applications because of their special properties, for example high strength-to-weight ratio, corrosion or erosion resistance, high-temperature resistance or hightemperature strength (Ref 1$)$. The joined materials are usually composed of layers made of two similar or dissimilar (in terms of chemical composition) materials (predominantly metals/ alloys or ceramic), which are permanently connected to each other. Using appropriate joining techniques, it is possible to produce finished elements in the form of the whole uniform product. An ability to join dissimilar materials enables to creation of lightweighting structures for automotive industry,

Aneta Szewczyk-Nykiel and Rafal Bogucki, Institute of Material Engineering, Tadeusz Kościuszko Cracow University of Technology, Al. Jana Pawła II 37, 31-864 Krakow, Poland. Contact e-mail: aneta.szewczyk-nykiel@mech.pk.edu.pl. modern medical implants, useful tools, equipment for consumers, and many other products (Ref 2-7).

Joining techniques may be also applied in powder metallurgy technology (Ref $1,3,5,7-10)$. It is important to note that the most significant property of sintered materials is porosity, because of the influence on the choice of joining process and quality of obtained joint $(\operatorname{Ref} 3,5,7,11)$. Sintered parts with density below $6.5 \mathrm{~g} \mathrm{~cm}^{-3}$ have the large pore volume. That is why, they should not be joined using methods related to local remelting. The recommended joining processes of these parts are diffusion welding, sinter-bonding, adhesive joining and brazing. The sintered parts with density higher than $7.2 \mathrm{~g} \mathrm{~cm}^{-3}$ can be welded. A wide variety of processes can be used to join in the case of intermediate density level (Ref 5). However, resistance projection welding and friction welding are preferred (Ref 3-5, 7, 11). It should be emphasized that using an additional joining operation (such as welding) has some disadvantage. It is a further step of production and needs appropriate devices so it entails an increase in product manufacturing cost (Ref 2, 5, 13).

In the case of the sintered parts, besides universal joining techniques such as welding or brazing, sinter-bonding and sinter-brazing are increasingly used (Ref 3-8, 12-26).

Sinter-bonding (also called sinter diffusion bonding) is a specific joining method applied only in powder metallurgy technology. It is increasingly being used on an industrial scale, especially by the largest manufacturers of sintered parts (Ref 3, $5,6,8)$. Usually, sinter-bonding relies on simultaneous sintering process of two green compacts, which are placed in furnace one on top of the other ( $\operatorname{Ref} 3,5,6,9)$. They can be prepared using the same or different powders (or powder mixtures). The connection between these green compacts is created during sintering as the result of solid-state diffusion, 
liquid-state diffusion or mechanical interlocking (Ref 3, 5, 8). Furthermore, the connection can be created using a bonding agent (which is placed between green compacts) or without it. It is also possible to joint green compact with part made of wrought material (Ref 5, 14). Sinter-bonding may be achieved by using different PM techniques such as conventional copressing and co-sintering (Ref 6, 8-10, 16), cold or hot isostatic pressing (HIP) (Ref 6), Spark Plasma Sintering (SPS) (Ref 1) or co-injection molding (Ref 17-26). It is considered that copressing and co-sintering of two materials are a beneficial solution because of simple production and lower cost in comparison with other fabrication methods (with addition joining operation). Furthermore, this method is also used to fabricate the sintered functionally gradient materials $(\operatorname{Ref} 3,5$, 6, 8-10).

The sinter-bonding behavior was studied by several authors (Ref 8-11, 13-16, 18-21, 23-26). In order to fabricate a desired microstructure and properties, different materials including iron (Ref 8-10, 23, 24, 26), low-alloy steels (Ref 8), high-alloy steels (Ref 8, 11, 13, 15, 16, 18-21, 23-26) as well as hardmetals (Ref 9, 10) were joined together during co-sintering. The studies focused on the influence of the techniques and conditions of sinter-bonding on an interface formation between two materials as a result of co-sintering, the densification, an evolution of microstructure as well as the microstructural characterization in order to achieve the crack-free complex products. It can be stated that sintering conditions have a significant effect on the densification and the co-sintering behaviors. Thus, they must be properly selected and controlled during co-sintering process (Ref 15, 24).

Using powder layering technique and co-pressing (for example, compaction with floating die, single-action as well as double-action mode of uniaxial pressing and cold isostatic pressing) or co-injection molding and then co-sintering, bimaterials components can be produced from AISI 316L and 17$4 \mathrm{PH}$ stainless steels powders (Ref 6, 15, 16, 20, 22-24). In this way, the joining of the two different materials can be combined with the production of complex-shaped components. It is an attractive and economical production method of the two-body products. AISI 316L and 17-4 PH steels have great industrial applications. They exhibit a good corrosion resistance and high strength. AISI $316 \mathrm{~L}$ is non-magnetic, while $17-4 \mathrm{PH}$ is magnetic. Products made as AISI 316L and 17-4 PH components could be magnetic properties at one area and nonmagnetic properties at another area. In order to achieve such products, it is necessary to select the appropriate parameters of co-pressing and co-sintering processes which enable to obtain a good solid connection in combination with the stability of the product shape.

Not much published information (Ref 6,15$)$ is available on the sinter-bonding of AISI 316L and 17-4 PH steels using a conventional PM, namely co-pressing and co-sintering processes. It should be noted that it is one of the most advantageous solutions because of low cost and simple production of elements. Based on a literature review, it can be stated that AISI 316L/17-4 PH components are usually produced by other PM techniques, mostly co-injection molding and then co-sintering (Ref 16, 20, 22-24).

The densification and microstructure of $316 \mathrm{~L} / 17-4 \mathrm{PH}$ bilayers were studied (Ref 15). They were produced using commercially available gas atomized stainless steel powders by co-pressing and co-sintering at temperatures ranging from 1100 to $1340{ }^{\circ} \mathrm{C}$ for $120 \mathrm{~min}$ in hydrogen and vacuum. The mismatch strain and strain rate of bilayer during co-sintering process were calculated. It was found that the strain rate of 17-4 $\mathrm{PH}$ was higher than that of $316 \mathrm{~L}$ during sintering. This caused mismatch strain between two layers and affected the densification rate of the bilayer. It should be pointed out that too high densification rate increases the danger of interface cracking and product deformation. It was found that materials should be sintered in a hydrogen atmosphere due to the higher density and the lower mismatch strain and strain rate between layers. 17-4 $\mathrm{PH}$ and $316 \mathrm{~L}$ steels show a similar sintering response with a maximum strain incompatibility of $0.5 \%$.

Based on a literature review, it can be stated that the influence of the pressing pressure was not analyzed and particular analysis of the influence of all sintering process parameters on densification, microstructure evolution or sintering compatibility of AISI $316 \mathrm{~L}$ and $17-4 \mathrm{PH}$ steels was not performed.

The present work concerns the application of sinter-bonding method to join dissimilar materials. The commercially available water atomized stainless steel powders of AISI 316L and 17-4 $\mathrm{PH}$ and the powder layering technique in combination with copressing and co-sintering were used to produce AISI 316L/17-4 $\mathrm{PH}$ components. The effect of co-pressing and co-sintering parameters on the densification, sintering compatibility and microstructural evolution of AISI 316L/17-4 PH components was investigated.

\section{Experimental Procedure}

Commercial available powders of 17-4 PH stainless steel (corresponding with standards: ASTM-A564 grade 630; UNS S17400) supplied by AMETEK and AISI 316L stainless steel (corresponding with standards: UNS S31603; EN 1.4404) provided by Höganäs were used. These grades of powders were produced by water atomization method. The chemical composition of applied powders is given in Table 1. Table 2 presents the typical properties of used powders. The powders of AISI $316 \mathrm{~L}$ and $17-4 \mathrm{PH}$ steels have a nominal particle size $<150 \mu \mathrm{m}$ (Table 3).

The powder layering method and co-pressing were used to prepare the green compacts. At first, a chamber of the die was filled by an appropriate amount of AISI 316L powder. In order to equalize powder on the top, the die was slightly shaken up. Then the powder was lightly pressed by manual pressure of upper punch. Afterward, an appropriate amount of 17-4 PH powder was added on the top of the flattened AISI 316L layer. The die was lightly shaken up once again, and then powders were uniaxially co-pressed in a rigid die at 400 or $600 \mathrm{MPa}$. In this way, the cylindrical samples with diameter of $20 \mathrm{~mm}$ and height of $5 \mathrm{~mm}$ were obtained. The volumes of both powders in green compact were almost the same. The green compacts were sintered in a Nabertherm furnace in a pure $(99.9992 \%)$ and dry (dew point below $-60{ }^{\circ} \mathrm{C}$ ) hydrogen atmosphere. The flow rate of the gas was $100 \mathrm{ml} / \mathrm{min}$. The isothermal sintering temperature was 1200,1250 or $1300{ }^{\circ} \mathrm{C}$. The sintering time was 60,90 or $120 \mathrm{~min}$. The samples were slowly heated to the isothermal sintering temperature at a rate of $5{ }^{\circ} \mathrm{C} / \mathrm{min}$. The same rate was applied during the cooling of the samples from sintering temperature to ambient temperature. 
Table 1 Chemical composition of AISI 316L and 17-4 PH powders (wt.\%)

\begin{tabular}{lllllllllllll}
\hline Material & $\mathbf{C r}$ & $\mathbf{N i}$ & $\mathbf{C u}$ & $\mathbf{M o}$ & $\mathbf{N b}$ & $\mathbf{S i}$ & $\mathbf{M n}$ & $\mathbf{C}$ & $\mathbf{S}$ & $\mathbf{P}$ & $\mathbf{F e}$ \\
\hline AISI 316L & 16.8 & 12.3 & $\ldots$ & 2.2 & $\ldots$ & 0.8 & 0.12 & 0.02 & $\ldots$ & $\ldots$ & bal. \\
$17-4 \mathrm{PH}$ & 16.28 & 4.28 & 4.04 & $\ldots$ & 0.32 & 0.73 & 0.05 & 0.027 & 0.011 & 0.015 & bal. \\
\hline
\end{tabular}

Table 2 Properties of AISI 316L and 17-4 PH powders

\begin{tabular}{lll}
\hline Material & Apparent density, $\mathbf{g ~ c m} \mathbf{~ c m}^{-\mathbf{3}}$ & Flowability, s/50 g \\
\hline AISI 316L & 2.67 & 29 \\
$17-4$ PH & 2.54 & 31 \\
\hline
\end{tabular}

Table 3 Sieve analysis, \%

\begin{tabular}{lcccc}
\hline Material & $<\mathbf{4 5} \boldsymbol{\mu m}$ & $>\mathbf{1 0 0} \boldsymbol{\mu m}$ & $\mathbf{1 5 0} \boldsymbol{\mu m}$ & \multicolumn{2}{c}{$00 \boldsymbol{\mu m}$} \\
\hline AISI 316L & 32 & 10 & 1 & 0 \\
$17-4$ PH & 30 & 9 & 1 & 0 \\
\hline
\end{tabular}

In order to compare the properties, the cylindrical samples were also prepared from AISI $316 \mathrm{~L}$ and $17-4 \mathrm{PH}$ powders as described above.

The density measurements of green compacts were carried out using the geometrical method. The sintered density and open porosity were measured by the water-displacement method (according to PN-EN ISO 2738:2001 norm). Before and after sintering, all samples were measured in order to estimate dimensional changes (PN-EN ISO 4492:2013-07E).

Dilatometric investigations were carried out in the horizontal NETZSCH 402E dilatometer.

Metallographic cross sections were prepared. The microstructural study of the investigated materials was done with Nikon Eclipse ME 600P Light Optical Microscope and SEM microscope JSM550LV produced by Joel. Using linear and point microanalysis (EDS), chemical composition was appointed along the line (perpendicular to the joining) passing through both layers.

\section{Results and Discussion}

Based on the literature review (Ref 6, 8, 16, 22, 25, 26), it can be stated that co-sintering of two dissimilar materials requires similarity of their densification behavior. These materials should have also similar sintering characteristics, for example, shrinkage rate as well as final shrinkage and the range of sintering temperature. It is important because of avoidance of interfacial stresses (Ref 16, 22, 25, 26). The control of the sintering shrinkage of both materials is necessary in order to ensure of appropriate densification and to avoid cracks or distortion. It can be stated that it is well founded to ensure an accurate control of heating and cooling rates during sintering process (Ref 6, 25).

Figure 1 shows the average values of green density for AISI 316L/17-4 PH components depending on the co-pressing pressure. For comparison, the results of green density measurement for each individual steel are also shown in Fig. 1. As expected, the pressing pressure significantly improves densification of green compacts. Independent of pressing pressure, AISI 316L steel has better compressibility than 17-4 PH. Although the green density value of AISI $316 \mathrm{~L} / 17-4 \mathrm{PH}$

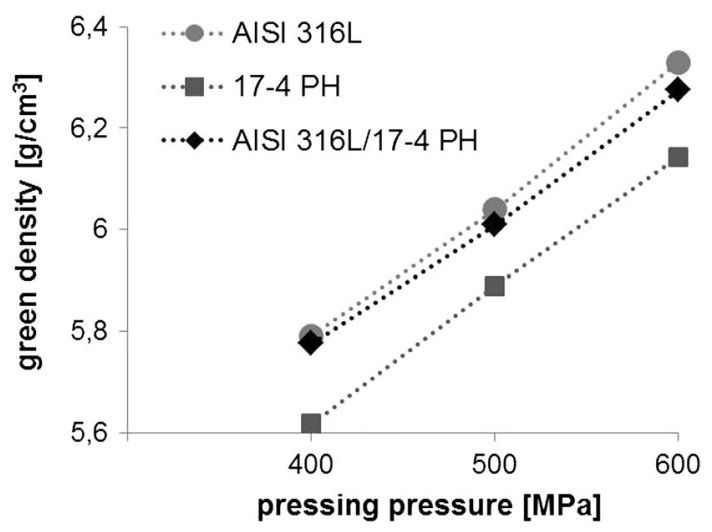

Fig. 1 Green density of studied materials as a function of pressing pressure

component is located between those for AISI 316L and 17-4 $\mathrm{PH}$ steels, it does not represent the average value. In fact, it is very close to green density value of AISI 316L steel.

Figures 2 and 3 show, respectively, the comparison of sintered density for AISI 316L/17-4 PH components and AISI $316 \mathrm{~L}$ and 17-4 PH steels (depending on the temperature and time of sintering process) in the case of pressing under pressure of 400 and $600 \mathrm{MPa}$. Here also, density of co-pressed and cosintered AISI 316L/17-4 PH component is between densities of AISI 316L and 17-4 PH steels. It is visible that it is not the average density of these stainless steels.

As expected, the increase in pressing pressure led to improve the sintered density of all studied materials. It should be noted that the difference between sintered density and green density was significantly greater (nearly twice) in the case of $400 \mathrm{MPa}$ pressing pressure in comparison with $600 \mathrm{MPa}$. Regarding influence of sintering conditions on density, longer time and higher temperature of sintering process contributed to an increase in density. As can be seen, the higher temperature and the longer time contributed to the more intensive density increase. This dependence was observed for each of studied materials. 


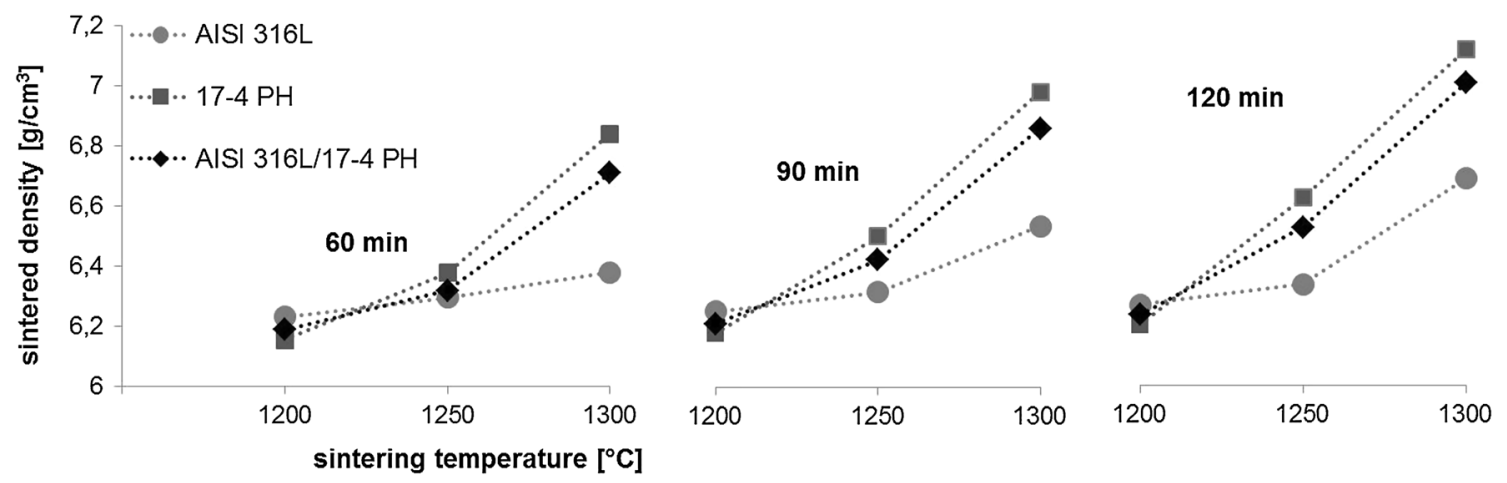

Fig. 2 Sintered density of studied materials as a function of the sintering conditions (pressing pressure of $400 \mathrm{MPa}$ )

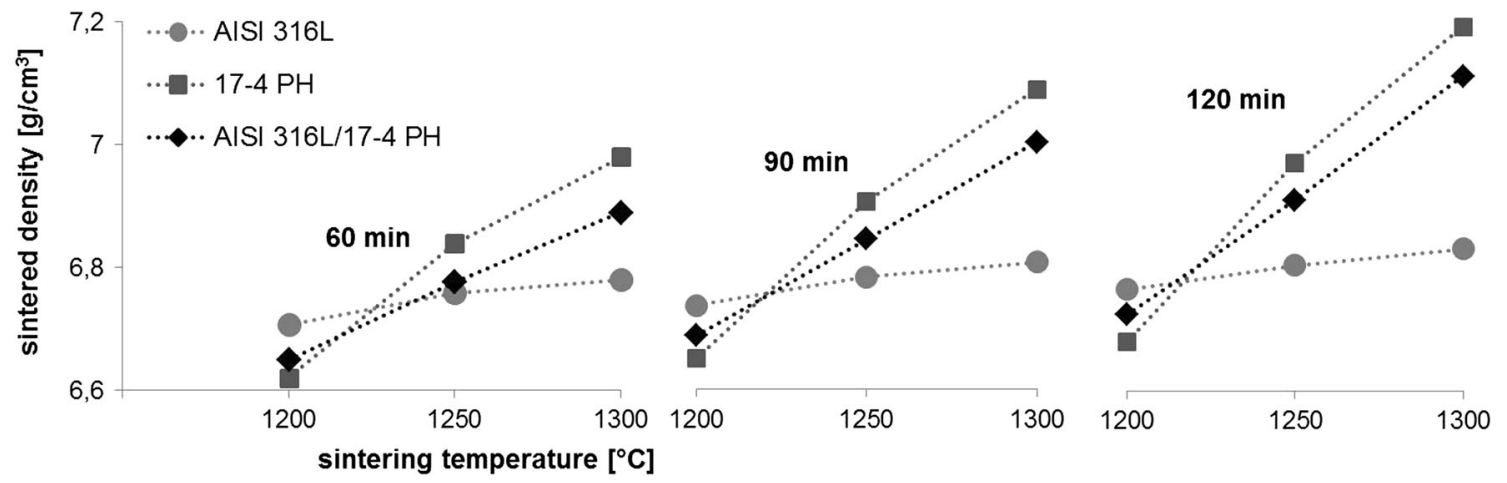

Fig. 3 Sintered density of studied materials as a function of the sintering conditions (pressing pressure of $600 \mathrm{MPa}$ )

It was observed that for AISI 316L steel the increase in sintered density as a result of increase in sintering temperature is insignificant in comparison with 17-4 PH steel. The same applies to the influence of increase in sintering time on density. These statements are true for both of applied pressing pressures. Independent of the used pressing pressure and sintering time, 17-4 PH steel sintered at $1200{ }^{\circ} \mathrm{C}$ possessed lower density than AISI $316 \mathrm{~L}$, whereas after sintering at 1250 and $1300{ }^{\circ} \mathrm{C}$, this relationship is inverse. It was found ( $\operatorname{Ref} 27,28)$ that $\delta$ ferrite is formed during the sintering of $17-4 \mathrm{PH}$ stainless steel in hydrogen atmosphere at a temperature above $1220{ }^{\circ} \mathrm{C}$. It occurs along the grain boundaries. The appearance of $\delta$ ferrite greatly enhances the sintering process, resulting in better densification and the elimination of pores. Hence, the sintering rate of 17-4 PH steel is greater than AISI 316L. It can be stated that longer time and higher temperature of sintering process contributed to a significant increase in density of AISI 316L/17-4 PH component. It is comparable to that for $17-4 \mathrm{PH}$ steel.

It is commonly known that the densification of material is strongly dependent on the sintering temperature (Ref 15). This was confirmed in work (Ref 20 ) relating to produce (by microco-injection molding) very small components in the following systems, 316L/17-4 PH and 316L/Fe (Ref 23, 24). The density of these components increases with the sintering temperatures and holding times.

It was observed an enhanced densification due to sintering shrinkage and compatibility between steels and interlayer diffusion of the alloying elements at high temperature in the case of co-sintering of composite layers containing M2 tool steel and 316L stainless steel (Ref 16).
Measurements of samples height were carried out before and after sintering process in order to designate dimensional changes. The results are presented in Fig. 4 and 5 depending on parameters of pressing and sintering process. In the case of all studied materials, the samples shrank after sintering. It can be seen that the amount of shrinkage (determined by means of $\Delta \mathrm{h}$ ) was different dependent on manufacture conditions. Generally, the shrinkage of samples was larger for 17-4 PH steel compared to AISI 316L. The shrinkage of AISI 316L/17-4 $\mathrm{PH}$ component is nearly comparable to the average shrinkage of individual steels regardless of sintering conditions.

It was found that after sintering at $1200{ }^{\circ} \mathrm{C}$ the difference between values of $\Delta \mathrm{h}$ for AISI $316 \mathrm{~L}$ and $17-4 \mathrm{PH}$ is almost the same regardless of other manufacturing conditions. While after sintering at $1250{ }^{\circ} \mathrm{C}$ for 90 as well as $120 \mathrm{~min}, 17-4 \mathrm{PH}$ steel exhibited much greater dimensional changes than AISI 316L steel. As might be seen, the sintering at temperature of $1300{ }^{\circ} \mathrm{C}$ (regardless of other manufacturing conditions) resulted in a significant difference between values of $\Delta \mathrm{h}$ for AISI 316L and 17-4 PH. In effect, the geometry of AISI 316L/17-4 PH component samples was altered. A conicity of the lateral surface appeared. It can be stated that the higher temperature and the longer time may result in some sintering incompatibility between AISI 316L and 17-4 PH steels and cause the appearance of cracks and warpage in the connection area.

The sintering compatibility of investigated stainless steels depends on the sintering temperature. It is visible that sintering at lower temperature ensured better sintering compatibility of studied materials in term of the shrinkage value but the densification was worse. The compatibility of different mate- 


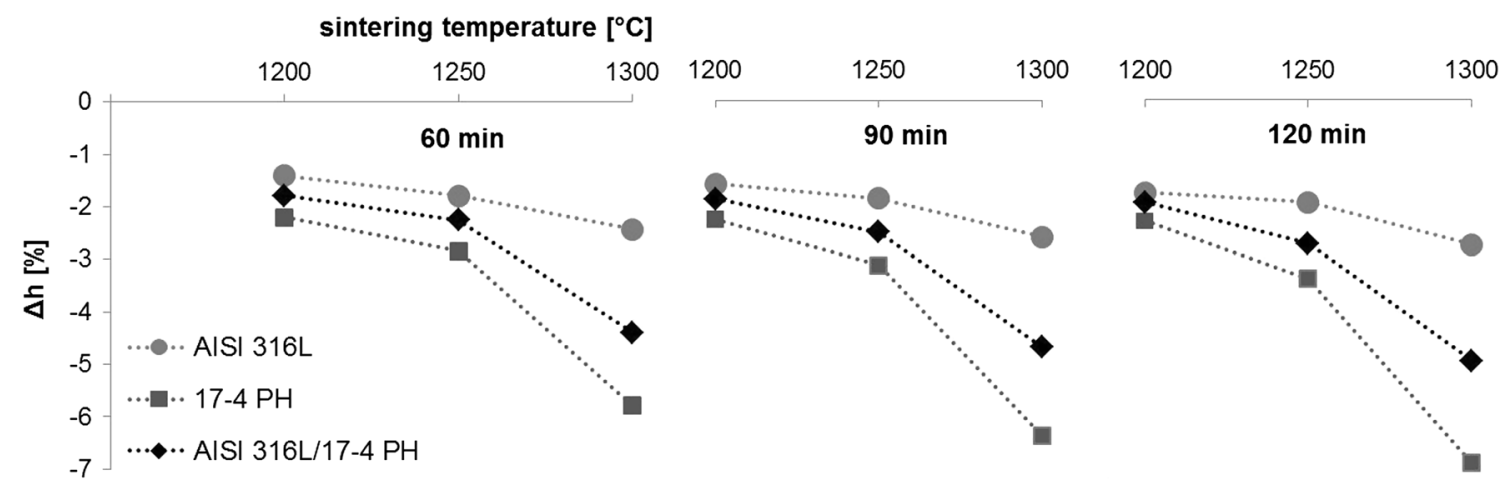

Fig. 4 Dimensional changes of samples as a function of the sintering conditions (pressing pressure of $400 \mathrm{MPa}$ )

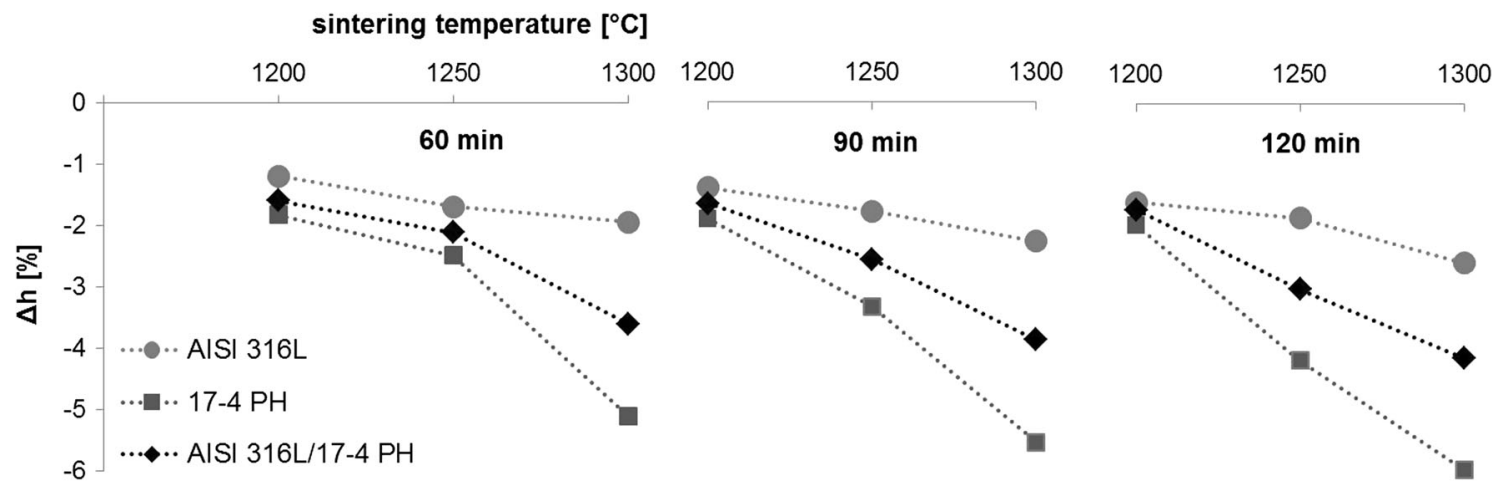

Fig. 5 Dimensional changes of samples as a function of the sintering conditions (pressing pressure of $600 \mathrm{MPa}$ )

Table 4 Dilatometry data of AISI 316L and 17-4 PH steels pressed at $600 \mathrm{MPa}$ and then sintered in hydrogen at $1250{ }^{\circ} \mathrm{C}$ for $60 \mathrm{~min}$

\begin{tabular}{lccccr}
\hline & \multicolumn{4}{c}{ Dimensional change, \% } & Temperature of start shrinkage, ${ }^{\circ} \mathbf{C}$ \\
\cline { 2 - 5 } & Heating & Isothermal sintering & Cooling & Total & Tem \\
\hline AISI 316L & 0.74 & 4.02 & 2.50 & 5.62 & 990.4 \\
$17-4$ PH & 1.52 & 3.66 & 1.93 & 6.27 & 947.4 \\
\hline
\end{tabular}

rials for sinter-bonding process was also investigated in terms of effect of material characteristic and conditions of production on the sintering behavior. For example, it was found that the maximum mismatch strain in $316 \mathrm{~L} / 17-4 \mathrm{PH}$ couple was $2.8 \%$, whereas it was $12.7 \%$ for $316 \mathrm{~L} / \mathrm{Fe}$ (Ref 23,24$)$. Thus, it was considered that the sintering compatibility between $316 \mathrm{~L}$ and 17-4 PH steels is appropriate for co-injection molding, while it is not suitable in the case of $316 \mathrm{~L}$ steel/iron couple. It turns out that a solid connection between two materials could be achieved by selection of appropriate materials as well as process parameters. It was demonstrated that formation of a solid connection between two materials is possible even if they exhibit relevant difference in chemical composition or in the sintering behavior (Ref 15, 19, 22).

The dilatometry is commonly used to determine the materials compatibility. Figure 6 shows the dilatometric curves of AISI 316L and 17-4 PH steels pressed at $600 \mathrm{MPa}$ and then sintered in hydrogen at $1250{ }^{\circ} \mathrm{C}$ for $60 \mathrm{~min}$. The presented curves show the dimensional changes occurring during sintering versus temperature. The data obtained during dilatometric study of AISI 316L and 17-4 PH steels are presented in

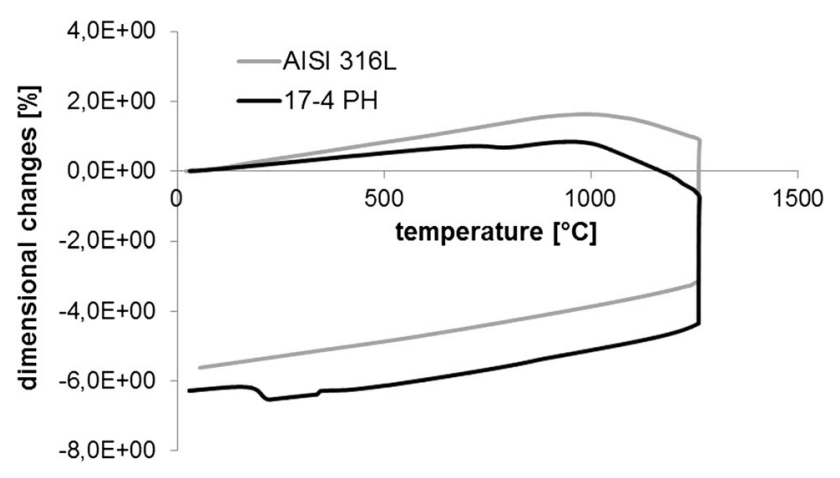

Fig. 6 Dilatometry curve of AISI $316 \mathrm{~L}$ and $17-4$ PH stainless steels (pressed at $600 \mathrm{MPa}$ and sintered in hydrogen at $1250{ }^{\circ} \mathrm{C}$ for $60 \mathrm{~min}$ )

Table 4. Dilatometric tests revealed the lower starting temperature of the sintering process and higher dimensional change during heating but the lower values of dimensional changes 


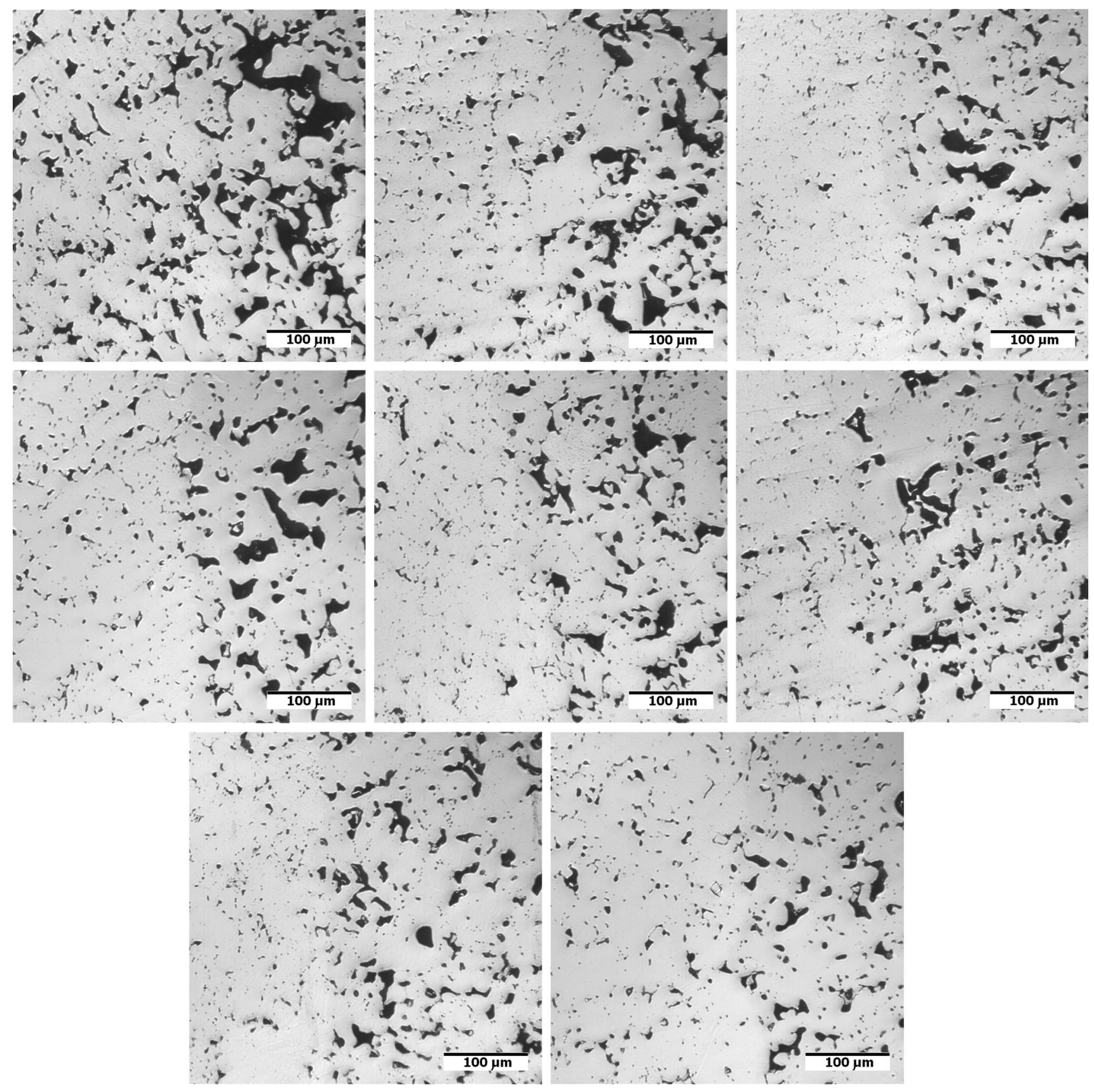

Fig. 7 Microstructures of AISI 316L/17-4 PH components depending on pressure of co-pressing, temperature and time of co-sintering process. The more porous layer is AISI $316 \mathrm{~L}$

during isothermal sintering and cooling for 17-4 $\mathrm{PH}$ steel in comparison with AISI 316L steel. The difference between values of total dimensional change for both steels is $0.65 \%$. It can be stated that 17-4 PH steel and AISI $316 \mathrm{~L}$ steels show a similar sintering response and their compatibility for sinterbonding process is favorable.

Figure 7 shows the microstructures (after mechanical polishing) of AISI 316L/17-4 PH components depending on conditions of co-pressing and co-sintering processes.

It can be observed that the layers of AISI $316 \mathrm{~L}$ and $17-4 \mathrm{PH}$ steels were strongly joined together in studied components during the high-temperature sintering. It was not found any cracks and warpage in the connection area for all studied AISI 316L/17-4 PH components. It means that regardless of processing conditions AISI 316L and 17-4 PH steels formed a correct connection.

It can be seen that AISI 316L steel possessed greater porosity compared to 14-7 PH steel, irrespective of pressing and sintering conditions. In AISI 316L steel layer, the pores have irregular shape and tend to interconnect, whereas they are considerably smaller, isolated and rounded in 17-4 PH steel layer. It is also noticeable that the porosity (in term of size and shape of pores) was changed due to changes in manufacturing conditions. Generally, it can be stated that the increase in all parameters of manufacture process has contributed to reduce the porosity of sintered steels.

An example of SEM microstructure with the intensity distribution of individual elements for AISI 316L/17-4 PH 

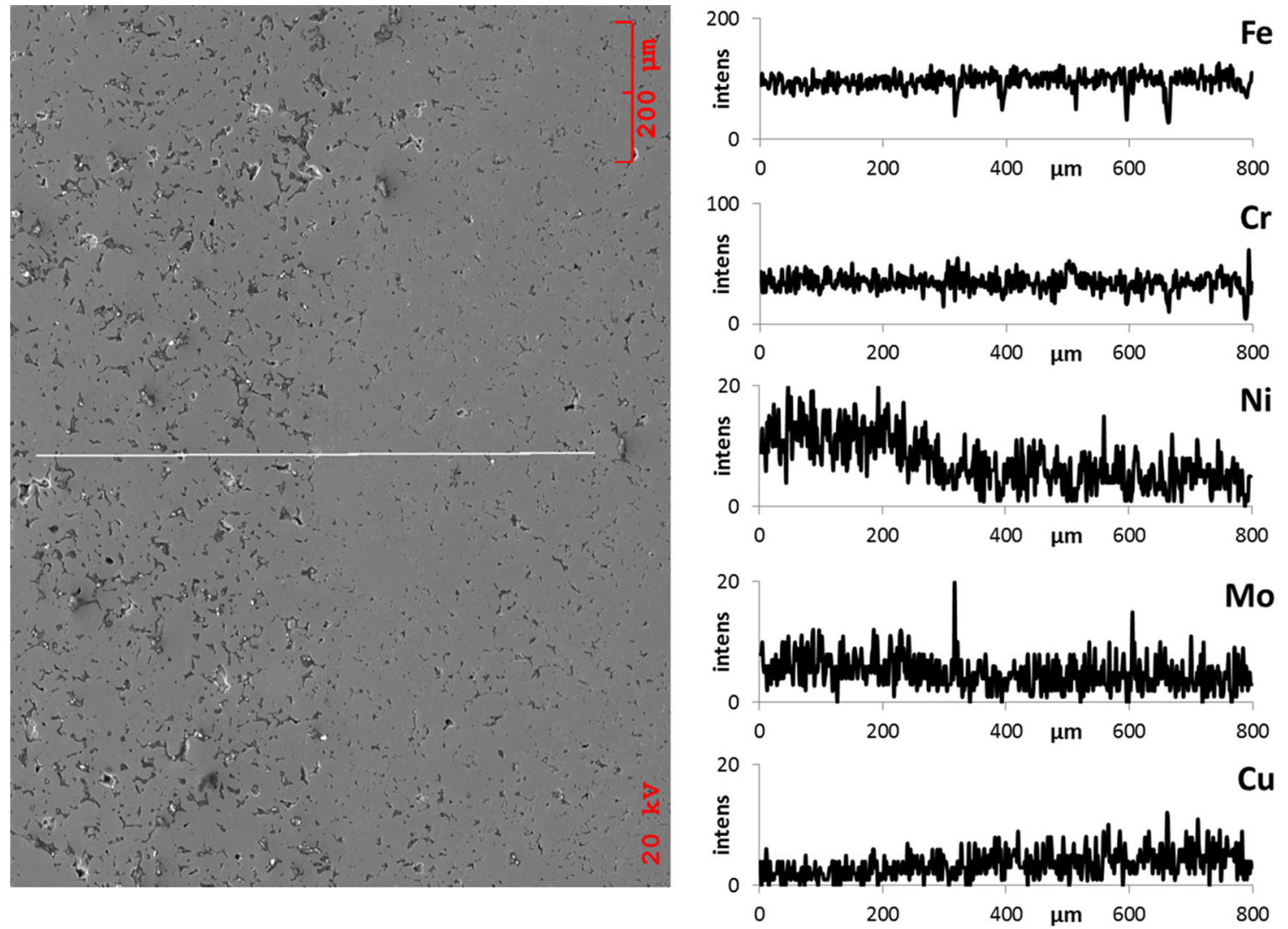

Fig. 8 The SEM microstructure of AISI 316L/17-4 PH component co-pressed at $400 \mathrm{MPa}$ and co-sintered at $1250{ }^{\circ} \mathrm{C}$ for $60 \mathrm{~min}$ and the intensity distribution of elements such as iron, chromium, nickel, molybdenum and copper

component is shown in Fig. 8. It is obvious that there is a substantial difference in the nickel level in studied stainless steels. (The content of nickel is lower in 17-4 PH than in AISI 316L.) Moreover, there is no copper in AISI 316L steel, and 17-4 PH is without molybdenum addition.

SEM microstructure of selected AISI 316L/17-4 PH component and the concentration profiles of the major elements, i.e., iron, chromium, nickel, molybdenum and copper are shown in Fig. 9. The concentration of nickel is low in the layer of 17-4 PH steel, then it continuously increases as it approaches the AISI $316 \mathrm{~L}$ side of the component and reaches the highest value in AISI 316L layer. (It confirms the nickel diffusion from AISI $316 \mathrm{~L}$ to $17-4 \mathrm{PH}$.) The same applies to molybdenum. While the change in the concentration of copper is reverse to that of the concentrations of nickel and molybdenum, whereas no changes in the concentration of $\mathrm{Cr}$ were observed. It has been shown that nickel and molybdenum diffuse into 17-4 PH and copper diffuses into AISI 316L. It visibly shows that the concentration of the above elements varies fluently passing from one layer of steel to another and the formation of an interdiffusion zone takes place.

The comparison of concentration profiles of nickel, copper and molybdenum across the interdiffusion zone in dependence of time and temperature of co-sintering process is presented in Fig. 10. It is evident from the profiles that a width of the interdiffusion zone in AISI 316L/17-4 PH component is influenced by the conditions of the isothermal co-sintering. Namely, in the case of lower temperature the width of this zone is smaller (about $50 \mu \mathrm{m}$ ), while it slightly increases to about $100 \mu \mathrm{m}$ in case of co-sintering at $1250^{\circ} \mathrm{C}$. The same is true for co-sintering time. It was found that the longer time as well as the higher temperature of co-sintering process result in wider interdiffusion zone in AISI 316L/17-4 PH components and nickel penetrates deeper into the 17-4 PH steel.

\section{Conclusions}

Using commercially available grades of stainless steels powders, AISI 316L/17-4 PH components were produced by a simple powder layering technique, co-pressing and then cosintering processes. The effect of production conditions on densification, dimensional changes and microstructural evolution of sintered AISI 316L/17-4 PH components was investigated.

The dilatometric study as well as dimensional changes measurements revealed an appropriate sintering compatibility for AISI $316 \mathrm{~L}$ and $17-4 \mathrm{PH}$ steels when the sintering process was carried out at the temperature of $1200{ }^{\circ} \mathrm{C}$ for time ranging from 60 to $120 \mathrm{~min}$ and at $1250{ }^{\circ} \mathrm{C}$ for shorter sintering times.

As expected, the density of AISI $316 \mathrm{~L} / 17-4 \mathrm{PH}$ components as well as individual steels increased with the increase in copressing pressure as well as co-sintering time and temperature. The sintering at temperature of $1300{ }^{\circ} \mathrm{C}$ (regardless of other manufacturing conditions) led to a great increase in material densification and creation of a solid good connection between AISI $316 \mathrm{~L}$ and 17-4 PH in studied components; however, sintering compatibility is not sufficient. In effect, a significant deviation from the cylindrical shape of samples appeared. It 

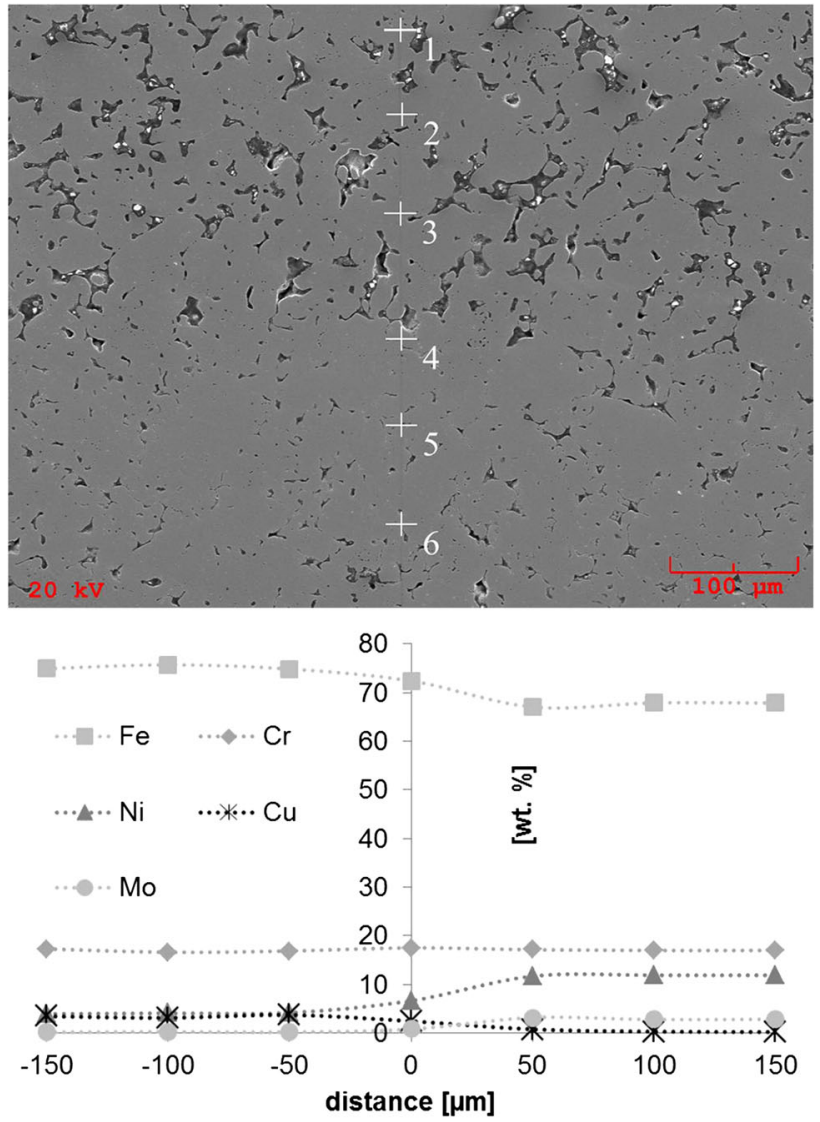

Fig. 9 SEM microstructure of AISI 316L/17-4 PH component copressed at $600 \mathrm{MPa}$ and co-sintered at $1250{ }^{\circ} \mathrm{C}$ for $60 \mathrm{~min}$ and the concentration profiles for iron, chromium, nickel, copper and molybdenum

should be noted that this infringement of sample shape is unfavorable from the application point of view. The solution of above-mentioned sintering compatibility problem may enhance the sintering process of AISI 316L steel, for example, by using a suitable activator (Ref 29). In effect, it should lead to an increase in shrinkage, densification after sintering; however, it should not impair the usable properties of the base material.

The microstructural study indicated that regardless of processing conditions AISI 316L and 17-4 PH steels create a good diffusion joint during the high-temperature co-sintering. There are not any cracks and warpage in the connection area. The concentration profiles of the main elements showed that nickel and molybdenum diffuse into the 17-4 $\mathrm{PH}$ and $\mathrm{Cu}$ diffuses into the AISI 316L. The interdiffusion zone is formed. It was found that the longer time as well as higher temperature of co-sintering process result in wider interdiffusion zone in AISI 316L/17-4 PH components and deeper penetration of nickel into the 17-4 PH steel.

It was demonstrated that it is possible to achieve a solid connection between two materials exhibiting difference in chemical composition by using sinter-bonding and conventional powder metallurgy technology.

\section{Open Access}

This article is distributed under the terms of the Creative Commons Attribution 4.0 International License (http://creativecom
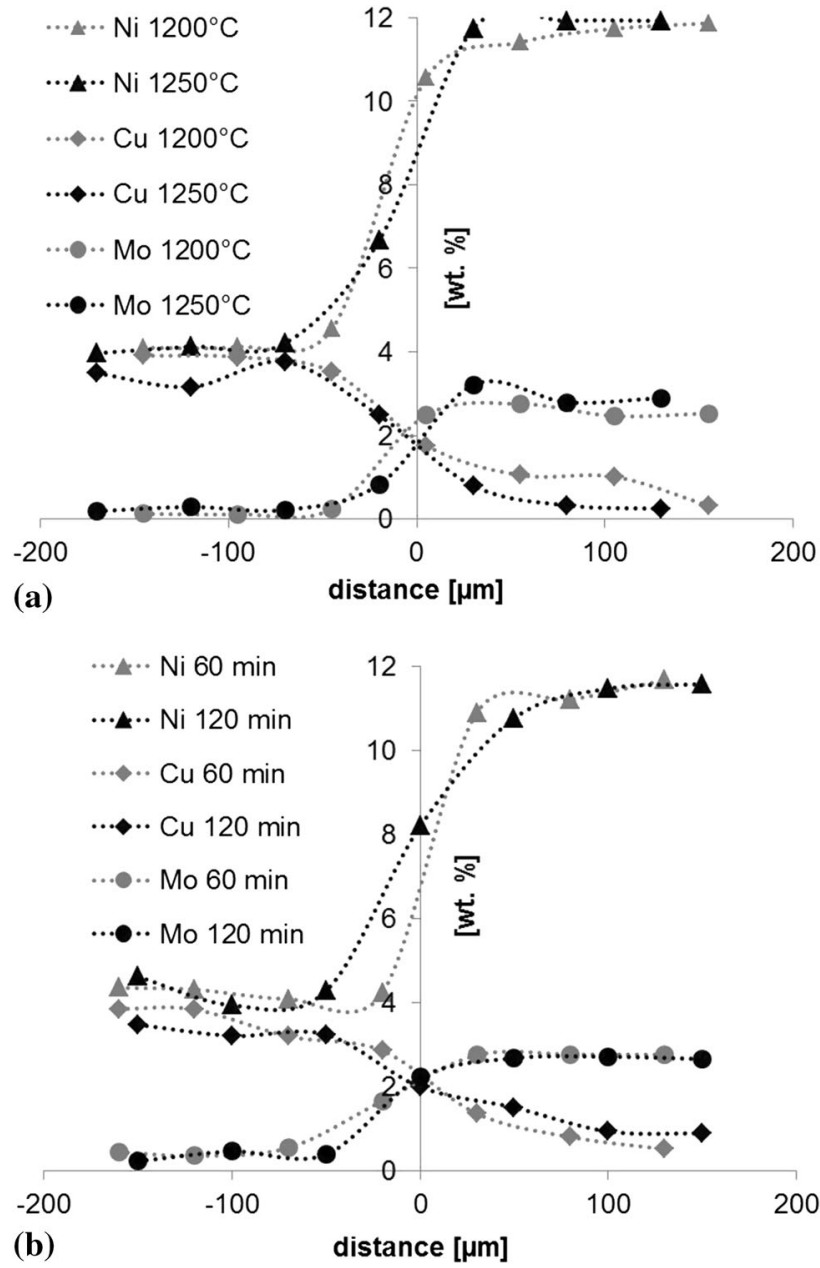

Fig. 10 The concentration profiles of $\mathrm{Ni}, \mathrm{Cu}$ and $\mathrm{Mo}$ for AISI 316L/17-4 PH component depending on: (a) temperature of co-sintering, (b) time of co-sintering

mons.org/licenses/by/4.0/), which permits unrestricted use, distri bution, and reproduction in any medium, provided you give appropriate credit to the original author(s) and the source, provide a link to the Creative Commons license, and indicate if changes were made.

\section{References}

1. K. Martinsen, S.J. Hu, and B.E. Carlson, Joining of Dissimilar Materials, CIRP Ann.-Manuf. Techn., 2015, 64, p 679-699

2. R.W. Messler, Joining of Materials and Structures from Pragmatic process to Enabling Technology, Butter Worth Heinemann, Burlington, 2004

3. J.A. Hamill, P/M Joining Processes, Materials and Techniques, Int. J. Powder Metall., 1991, 27(4), p 363-372

4. J.A. Hamill, What are the Joining Processes, Materials and Techniques for Powder Metal Parts?, Weld. J., 1993, 72(2), p 37-45

5. T. Pieczonka, Procesy spajania w metalurgii proszków (bonding processes in powder metallurgy), Rudy i Metale Nieżelazne, 2003, 48(9), p 435-448 (in Polish)

6. E. Yalamac, P.C. Carry, S. Akkurt, Co-Pressing, Co-Sintering and Characterization of Bi-Materials, 14th International Materials Symposium (IMSP'2012), 2012 (Denizli, Turkey)

7. C. Selcuk, S. Bond, P. Woollin, Critical review of joining processes for powder metallurgy parts, Euro PM 2008 Congress and Exhibition, 2008 (Mannheim, Germany) 
8. T. Pieczonka and J. Kazior, Sinter-Bonding of Iron Based Compact Containing $\mathrm{P}$ and $\mathrm{Cu}$, Mater. Sci. Forum, 2007, 534-536, p 633-636

9. Y. Kamdem, D. Bouvard, P. Doremus, D. Imbault, and F. Doré, Production of bi-Material Tubular Structures by Powder Metallurgy, Powder Metall., 2010, 53(4), p 274-277

10. A. Thomazic, Y. Le Guennec, Y. Kamdem, C. Pascal, J.M. Chaix, P. Doremus, D. Imbault, D. Bouvard, and F. Doré, Fabrication of bimaterial components by conventional powder metallurgy, International Powder Metallurgy World Congress and Exhibition-PM2010, 2010 (Florence, Italy)

11. C. Selcuk, S. Bond, and P. Woollin, Joining Processes for Powder Metallurgy Parts: A Review, Powder Metall., 2010, 53(1), p 7-11

12. F. Findik, Recent Developments in Explosive Welding, Mater. Des., 2011, 32(3), p 1081-1093

13. M. Roudbari, A. Mehdipoor, and R. Azarafza, Heat Treatment of Stainless Steel 316L-Titanium Bimetal Manufactured by Explosive Welding, Int. Res. J. Appl. Sci., 2013, 7(10), p 687-692

14. K. Asaka, Diffusion Bonding Methods of Green Compacts with Wrought Steel Parts During Sintering, J. Jpn. Soc. Powder Metall., 1995, 42(4), p 522-527

15. A. Simchi, A. Rota, and P. Imgrund, An Investigation on the Sintering Behavior of $316 \mathrm{~L}$ and $17-4 \mathrm{PH}$ Stainless Steel Powders for Graded Composites, Mater. Sci. Eng. A, 2006, 424, p 282-289

16. V. Firouzdor, A. Simchi, and A.H. Kokabi, An Investigation of the Densification and Microstructural Evolution of M2/316L Stepwise Graded Composite During Co-Sintering, J. Mater. Sci., 2008, 43, p 5563

17. T. Martens and M.L. Mears, Direct Sinter Bonding of Metal InjectionMolded Parts to Solid Substrate Through Use of Deformable Surface Microfeatures, J. Micro Nano-Manuf., 2013, 1(1), p 1-10

18. S.X. Zhang, T. Li, Q.F. Li, S.F. Pook, C.W. Goh, and Q.J. Hu, Joining of Two Materials by Powder Injection Moulding, Sci. Technol. Weld. Join., 2009, 14(1), p 11-19

19. A. Simchi, F. Petzoldt, T. Hartwig, Metal Injection Moulding: An Approach for Assessment of Sintering Behavior of Co-injection Moulded PIM Feedstocks by Dilatometric Analysis, European Congress and Exhibition on Powder Metallurgy, The European Powder Metallurgy Association, 2005 (Shrewsbury), p 365-370
20. G. Benedet Dutra, M. Mulser, and F. Petzoldt, Interface Formation and Diffusion of Alloying Elements During Co-Sintering of MIM 316L/174PH Stainless Steel Parts: Experiments and Simulation, Powder Metall., 2011, 54(5), p 614-619

21. A. Laik, P.S. Gawde, K. Bhanumurthy, and G.B. Kale, Characteristics of Interdiffusion Between 17-4 PH Steel and Nickel, Metall. Mater. Trans. A, 2008, 39A, p 733-741

22. Ph. Imgrund, A. Rota, Th. Hartwig, F. Petzoldt, and A. Simchi, Metal Injection Moulding: Adjustment of Materials and Sintering Processes for MIM of Bi-Material Parts, European Congress and Exhibition on Powder Metallurgy, The European Powder Metallurgy Association, 2005 (Shrewsbury), p 315-320

23. Ph. Imgrund, A. Rota, and L. Kramer, Processing and Properties of Bimaterial Parts by Micro Metal Injection Moulding, First International Conference on Multi-Material Micro Manufacture, 2005 (Germany), p 131-134

24. Ph Imgrund, A. Rota, and A. Simchi, Microinjection Moulding of $316 \mathrm{~L} / 17-4 \mathrm{PH}$ and $316 \mathrm{~L} / \mathrm{Fe}$ Powders for Fabrication of MagneticNonmagnetic Bimetals, J. Mater. Process. Technol., 2008, 200, p 259264

25. R.M. German, D.F. Heaney, and J.L. Johnson, Bi-material Components Using Powder Injection Molding: Densification, Shape Complexity, and Performance Attributes, Adv. Powder. Metall. Part. Mater., 2005, 1(4), $p$ 41-52

26. D.F. Heaney, P. Suri, and R.M. German, Defect-Free Sintering of Two Material Powder Injection Molded Components Part I, Experimental Investigations, J. Mater. Sci., 2003, 38, p 4869-4874

27. A. Szewczyk-Nykiel, S. Gądek, M. Hebda, M. Nykiel, and J. Kazior, Investigation of Densification of 17-4 PH Stainless Steels Powders During Sintering in Vacuum and in Hydrogen, Mater. Eng., 2012, 33(5), p 469-472 (in Polish)

28. A. Szewczyk-Nykiel and J. Kazior, Effect of Aging Temperature on Corrosion Behavior of Sintered 17-4 PH Stainless Steel in Dilute Sulfuric Acid Solution, J. Mater. Eng. Perform., 2017, 26, p 3450-3456

29. A. Szewczyk-Nykiel, M. Skałoń, and J. Kazior, Corrosion Behaviour of Sintered AISI, 316L Stainless Steel Modified with Boron-Rich Master Alloy in $0.5 \mathrm{M} \mathrm{NaCl}$ Water Solution, Arch. Metall. Mater. 2015, 60(3), p 1795-1800 